Como citar este artículo en APA: Fernández Hart, R. (2019). La santidad perdida. Una revisión crítica de lo sagrado. Cuestiones Teológicas, 46 (105), 101-123. doi: http://dx.doi.org/10.18566/cueteo.v46n105.a04

Fecha de recepción: 27.02.2019 Fecha de aceptación: 07.03.2019

\title{
LA SANTIDAD PERDIDA UNA REVISIÓN CRÍTICA DE LO SAGRADO
}

\author{
Lost Holiness: A Critical Review of the Sacred \\ A santidade perdida. Uma revisão crítica do sagrado
}

Rafael Fernández Hart, SJ ${ }^{\mathrm{I}}$

1 Doctor en Filosofía por el Centre Sevres - Facultés Jésuites de París. Decano de la Facultad de Filosofía, Educación y Ciencias Humanas de la Universidad Antonio Ruiz de Montoya (Perú).

Correo electrónico: rafael.fernandez@uarm.pe 


\section{Resumen}

Lo sagrado ha sido considerado una categoría esencial para estudiar y comprender las religiones. Este punto de partida ha hecho pensar que incluso las religiones que carecen de una noción de divinidad conservan su dimensión sagrada. El presente artículo intenta volver sobre lo sagrado, pero con el fin de demostrar algunas dificultades de esta categoría cuando se intenta penetrar en el sentido ético-espiritual de las religiones. De este modo, con el fin de ofrecer una mejor comprensión de las religiones se opera un desmontaje de lo sagrado por el que se reactiva la categoría de la santidad. Esta categoría asegura no solo otro acercamiento a las religiones, sino que permite entender por qué aparece con insistencia la espiritualidad en el escenario actual. Así, pues, nos proponemos profundizar en las ramificaciones y manifestaciones culturales de lo sagrado así como emitir una crítica de la realidad sagrada para elaborar filosóficamente el concepto de santidad. Dicho concepto explica mejor lo que son las religiones.

Palabras clave: Sagrado, Santo, Santidad, Espiritualidad, Infinito.

\section{Abstract}

The sacred has been considered a fundamental category to study and understand religions. Such starting point has led to consider that even religions that lack an idea of divinity, keep their sacred dimension. This article re-considers the sacred with the purpose of showing some difficulties this category might face when used to get into the ethical-spiritual sense of religions. Therefore, aiming at a better understanding of religions, the article dismantles the category of the sacred and reactivates that of holiness. The latter not only guarantees an approach to religions, but also makes possible to understand why spirituality frequently appears in contemporary scenarios. Thus, the article delves into the cultural ramifications and manifestations of the sacred and provides a critique of sacred reality to philosophically develop the concept of holiness. The latter explains better what religions are.

Key Words: Sacred, Holy, Holiness, Spirituality, Infinite. 


\section{Resumo}

O sagrado tem sido considerado uma categoria essencial para estudar e compreender as religióes. Esse ponto de partida tem feito pensar que mesmo as religióes que náo têm uma noção de divindade conservam sua dimensão sagrada. O presente artigo tenta voltar sobre o sagrado, mas no intuito de demostrar algumas dificuldades desta categoria quando penetra-se no sentido ético-espiritual das religióes. Desse modo, a fim de oferecer uma melhor compreensão das religióes se desmonta o sagrado para reativar a categoria da santidade. Essa categoria garante não só outra abordagem das religiôes, mas que permite entender porquê aparece a espiritualidade com persistência no cenário atual. Por conseguinte, propomos aprofundar nas ramificaçōes e manifestações culturais do sagrado, assim como, emitir uma critica da realidade sagrada para elaborar filosoficamente o conceito de santidade. Esse conceito explica melhor o que são as religióes.

Palavras-chave: sagrado, santo, santidade, espiritualidade, infinito.

\section{Conocer y desmontar lo sagrado}

No podemos desentendernos de la animalidad y de los "vicios bestiales" (Kant, 1981, p. 35) que se sobreponen en nuestra disposición específica hacia la vida. La pregunta que hay que hacerse es: ¿cómo la cultura entra en connivencia con la brutalidad para prolongarla a través de distintas facetas que van desde la corrupción hasta el (deseo de) asesinato? Bajo inspiración de Girard y de Lévinas, se puede decir que la cultura nació y ha seguido atada a la ambigüedad de lo sagrado. Más aún, la historia ha develado que lo sagrado disimuló su ambigüedad intrínseca que linda con la violencia (Girard, 1998). Así, lo sagrado no es solo lo que está separado, consagrado, sino lo que se reserva una ambivalencia expresada en pares como puro-impuro, benéficomaléfico, tremendo-fascinante, entre otros. Se puede decir, todavía con más claridad, que el mundo de lo sagrado carece de salida, de exterioridad, de palabra y del otro (Chalier, 2006, p. 542). Lo sagrado explica en gran parte la violencia en nuestras relaciones interpersonales. 
Ahora bien, la tesis que aboga por la unidad entre la violencia y lo sagrado ha sido puesta en evidencia por varios intelectuales, entre quienes destaca René Girard (1998, p. 51). Después de descubrir la naturaleza triangular del deseo (1985, p. 10), el autor francés muestra que el carácter imitativo del deseo nos conduce hasta la amenaza de la rivalidad. Si es cierto que lo que deseo es deseado por otro, por lo tanto, mi deseo no es singular ni original, sino repetición del deseo de otro. A este respecto, ya que el deseo no me hace único, nunca sería más oportuna la recordada afirmación nietzscheana del eterno retorno de lo mismo.

Pero la situación de repetición en la que nos ubica el deseo provoca que nos miremos mutuamente como una posible amenaza. Este aserto es defendido, según sus modelos filosóficos, no solo por Hobbes (homo homini lupus) o Girard (violencia recíproca), sino por Lévinas para quien siempre puedo ser asesino del otro (egoísmo ontológico).

De acuerdo con Girard, en virtud de este despliegue específico del deseo como copia, se produce un proceso de homogenización o de indiferenciación que aumentará paulatinamente la amenaza de muerte. De esta manera, el otro deviene en escollo que, tarde o temprano, se deberá eliminar; por lo tanto, nos constituimos en riesgo potencial para el otro ya que podemos ser su asesino. Esto explica la taxativa tesis girardiana según la cual toda cultura comenzó por un asesinato primordial o fundacional y que este es puesto a la luz, en primer lugar, por la literatura. Pero al mismo tiempo, no deja duda con respecto a que el primer gesto cultural es también religioso y simbólico: el gesto original sobre el que se funda la cultura es lo sagrado (el sacrificio); lo que Girard llama la violencia pura o permitida. ¿Cómo nace esta violencia como gesto cultural?

Ya que el homo sapiens circula en el planeta desde hace más de 100 mil años, lo sagrado llega al final de un proceso de hominización más bien lento y largo. En este sentido, es difícil defender que las primeras hordas hayan tenido la cualidad para constituir un aparato cultural complejo, pero sí que fueron capaces de convertir la violencia impura y autodestructiva en otra más bien pura y dirigida contra un objetivo común y distinto de la dicha horda. Esta violencia dirigida es la que aseguró la sobrevivencia de la especie; fruto de un desplazamiento no previsto, la violencia se hizo unánime 
y salvífica aunque haya condenado a muerte a un chivo expiatorio, a una víctima emisaria que devendrá en el primer sagrado (puro-impuro ${ }^{2}$ ) y en el primer símbolo (primera vez que algo está en lugar de otra cosa ${ }^{3}$ ). Esta irrupción sagrada y simbólica marca la aparición de la religión, su primera intervención histórica.

Así, en estrecha relación con el pensamiento de Girard, la religión ha sido el gesto necesario para poner a salvo a la humanidad frente a su propia violencia. Pero la religión no nos ha liberado de toda violencia ya que la cultura no ha perdido su impronta sacrificial. ${ }^{4}$ Podría decirse que la cultura fue y es sacrificial una vez y para siempre, a menos que sea posible romper con la influencia de lo sagrado. ¿Será ello posible? Es decir, ¿será posible salir del todo de la violencia aunque ella sea permitida? Nuestra respuesta se encuentra en la santidad como categoría espiritual.

Lévinas (1991), con el fin de dar cuenta de lo que entiende por lo sagrado, recuerda a Lévy-Bruhl quien sostiene que entre los primitivos adheridos a lo sagrado, "ser es participar" (p. 60). "Para el individuo, la participación 'es una condición de su existencia, quizás la más importante, la más esencial [...] Para esta mentalidad, existir es participar de una fuerza, de una esencia, de una realidad mística"'5 (p. 59). Pero precisamente por esta razón, el individuo - capaz de libertad y decisión-sucumbe bajo la fascinación del espejismo sagrado; el individuo se somete a lo sagrado y le somete también todo lo que está alrededor con el fin de constituir una totalidad.

2 Puro porque aporta la paz, es decir, la salvación en el seno de la comunidad; impuro porque, inicialmente, había traído la violencia.

3 Se ha sacrificado un sustituto en su lugar.

4 No debemos olvidar que Kant en La religión dentro de los límites de la mera razón señala que nuestra disposición a la humanidad supone la posibilidad de la comparación; sobre esta disposición al bien como humanidad se adhiere la rivalidad (1981). La comparación es una forma de la mimesis de acuerdo con nuestro modo de ver.

5 Hay que subrayar que la presente cita de Lévinas muestra su crítica a la mística que, según su comprensión, no es otra cosa que la prolongación de sentimientos y emociones que embargan al sujeto e impiden actuar libremente. Es también una forma de subsumir lo santo. 
Después de todo, la primera y la única totalidad, el único totalitarismo de ayer y hoy es el de lo sagrado, ya se trate de la religión primitiva o moderna, de las cruzadas, del nacionalsocialismo o simplemente del neoliberalismo contemporáneo.

Estas realidades nos retrotraen a la misma unidad sagrada, a la misma totalidad, y en toda manifestación de este tipo encontramos repeticiones de un sistema en el que el individuo se hace uno con la totalidad. Es imposible evadir estas totalidades sin desmontar el origen de lo sagrado. Un universo en el que los individuos son absorbidos por una totalidad no puede ser otra cosa más que un mecanismo que ha suprimido la libertad, esto es, la posibilidad de elegir como ocurre con el mal banal que grafica Arendt en Eichmann en Jerusalén. ${ }^{6}$ Lo sagrado al hacerse una totalidad impide el ejercicio de la voluntad libre.

Pero lo sagrado no puede domeñar al individuo que acepta ser imputable, ya que en este gesto reconoce el carácter inalienable de su responsabilidad, es decir, se diferencia de la totalidad que constituye lo sagrado.

A esta altura es legítimo plantear una hipótesis por la que quisiéramos reconquistar el término de "santidad", 7 cuyo uso acaso haya sido de otro tipo. La santidad consiste en una ruptura voluntaria de la suficiencia sagrada ya que es el único itinerario posible para constituirse en un sujeto imputable. ${ }^{8}$

6 "No, Eichmann no corrió "peligro de muerte inmediata», y como sea que aseguraba con gran orgullo que siempre "había cumplido con su deber», que siempre había obedecido las órdenes, tal cual su juramento exigía, siempre había hecho, como es lógico, cuanto estuvo en su mano para agravar, en vez de aminorar, 'las consecuencias del delito"” (2003, p. 58).

7 "Para Lévinas, es imperativo que reconozcamos la distinción entre lo sagrado y lo santo porque es precisamente esta última idea la que el judaísmo ha recomendado tradicionalmente como antídoto contra la evasión ética que alienta lo sagrado" (Caruana, 2006, p.570; Trad. propia).

8 Lévinas inspira también nuestra idea de santidad: "A esta apertura hacia la santidad, una trascendencia tan elevada y fuera de alcance que al mismo tiempo nos toca como un inmemorial, sin el cual no habría memoria, Lévinas terminará por darle el nombre de santidad. La santidad es como el superlativo de la diferencia. Lo santo no tiene nada que ver con la voracidad de lo sagrado" (Petitdemange, 1997, p. 242; Trad. propia). 
Pero, precisamente por eso, el ejercicio de esta santidad, es un acceso a otro nivel de conciencia y de práctica psicoespiritual. ${ }^{9}$ Por lo tanto, contener o incluso desmontar lo sagrado es posible en virtud de la santidad; pero, ¿de qué manera? Eso es lo que debemos responder.

\section{Cómo emerge la santidad}

En virtud de la secularización se ha desvelado tanto la fragilidad de lo sagrado como sus diferentes manifestaciones y mecanismos de coerción sobre el sujeto. En efecto, lo sagrado ha perdido su capacidad de influjo social de una manera determinante, de allí que nos encontremos en una era en la que abundan las búsquedas espirituales sin referencia a este absoluto $^{10} \mathrm{o}$ a aquellos

9 A la luz de Platón y Aristóteles, al-Fârâbî hacía una distinción entre los pocos y los muchos. Esta distinción no es nueva y sobre todo ha tenido diferentes reediciones en la historia del pensamiento. Pero no es esto lo que queremos decir cuando nos referimos a otro nivel de conciencia psicoespiritual; es decir no pretendemos justificar una diferencia entre las posibilidades o capacidades que existen entre seres humanos. Sin embargo, sí habrá que reconocer que hay una diferencia en cuanto a las habilidades actuales entre las personas debido en parte a la inexistencia de una práctica. El mismo al-Fârâbî lo reconoce: "Por razón de lo que se ha dicho acerca de la diferencia de las disposiciones naturales en los hombres individuales, no todo hombre puede por naturaleza conocer espontáneamente la felicidad ni las cosas que debe hacer, sino que para ello necesita de un maestro y de un guía. Algunos necesitan poca instrucción, mientras que otros requieren mucha. Y cuando es guiado hacia esas dos cosas, indudablemente ni siquiera hará aquello que ha conocido y hacia lo que ha sido guiado sin una motivación externa y algo que le impulse a ello. Así son muchos hombres. Por eso necesitan que alguien les dé a conocer todo eso y les impulso a hacerlo" (2009, p. 102). Desde una perspectiva muy distinta y a partir de una metafísica cristiana, Paul Chauvin subraya que la santidad es una disposición "habitual" del alma, y además, que la santidad no es diferente del espíritu de la religión (Chauvin, 1904, p. 11).

10 Lo que señala más precisamente Charles Taylor (2003) es lo siguiente: “Dentro del nuevo orden [actual] se abandona el principio a priori según el cual toda respuesta válida a las inquietudes religiosas debe darse dentro de las condiciones paleo o neodurkheimianas (una Iglesia, o una 'Iglesia' y/o una sociedad). Lo espiritual en cuanto tal ha dejado de estar intrínsecamente vinculado a la sociedad” (p. 111). Las 
espacios que tradicionalmente nos lo ofrecían. Ahora bien, aunque en crisis, lo sagrado ha logrado disimularse, pero su repliegue actual ha permitido que podamos comprender algo mejor su estrategia de supervivencia. Se ha podido hacer evidente que lo sagrado había tomado un lugar que no era suyo, porque se hizo objeto de culto al suprimir al individuo y su capacidad de agencia libre. ${ }^{11}$ Lo sagrado usurpó el lugar del individuo; de algún modo, se puede decir que también despojó de su lugar a la santidad. Es verdad que los términos "santo" o "santidad" son poco usuales para una reflexión filosófica; por esta razón procederemos a elaborar el término.

Sobre la santidad, Lévinas (1977) se pregunta si ella, es decir, "la esencia sin mezcla que podemos llamar Espíritu y que anima el judaísmo", puede habitar en un mundo que no se haya desacralizado primero (p. 89; Trad. propia). Esta pregunta, solo en apariencia ingenua, obliga a pensar en cierto grado de incompatibilidad entre la santidad y lo sagrado; e incluso, quizás, sea necesario ir más lejos, ya que parece que la condición de posibilidad de la santidad es la secularización o la desacralización. Lévinas propone en sordina ir más lejos: ¿será posible suprimir o, al menos, contener lo sagrado? Eso es lo que ha dejado esbozado el filósofo lituano-francés en otro magnífico aserto: "[...] la filosofía deriva de la religión e impide que la religión vaya a la deriva" (1977, p. 156; Trad. propia). ${ }^{12}$ Por medio de esta afirmación no solo explica el orden histórico por el que todo viene de la religión, acaso en el mismo sentido de Girard, sino que la religión (y en particular, lo

búsquedas espirituales han adquirido un carácter hiper-individualizado en el que la totalidad sagrada parece haber perdido su posibilidad de dominar. Pero solo se trata de otro espejismo peligroso. A propósito de las nuevas y abundantes búsquedas espirituales se puede también revisar el interesante trabajo de Comte-Sponville (2006) El alma del ateísmo. Introducción a una espiritualidad sin Dios.

11 En la filosofía de Lévinas lo sagrado subsume la santidad. De allí pues su reacción en contra de la sociología de la religión francesa que no ha percibido la distancia entre lo sagrado y lo santo (Caruana, 2006, p. 564). Se trata de una diferencia ético-espiritual que nos atrevemos a comparar al descubrimiento heideggeriano de la diferencia ontológica (el ser no es nada de ente): lo santo no es nada de sagrado.

12 No debería sorprendernos este razonamiento en el filósofo que ha dado un lugar preponderante al rostro en el que puede adivinarse una excelencia sin comparación. En efecto el "rostro humano [...] detiene la violencia y el crimen enseñando la santidad o mandándola” (Lévinas, 1989, p. 359). 
sagrado) requiere al mismo tiempo de contención porque de suyo andará a la deriva y nos arrastrará con ella haciendo de nosotros esclavos del fatum sagrado; o peor aún, prisioneros de la violencia sagrada que emana de una tesis totalitaria. La santidad es un itinerario que exige disciplina. Cuando Lévinas (1977) en su artículo "Desacralización y desembrujo" se refiere a la brujería como prima hermana, o incluso, hermana de lo sagrado, no duda en señalar que la sociedad desacralizada

[...] sería una sociedad en la que se detendría el mecanismo impuro de la brujería, presente en todas partes, que hace vivir en lugar de alienar lo Sagrado. La verdadera desacralización intentaría separar positivamente lo verdadero de la apariencia, incluso trataría de separar lo verdadero de la apariencia esencialmente mezclada con lo verdadero (p. 90; Trad. propia).

Esta mezcla confusa de puro e impuro, este hecho anónimo, ${ }^{13}$ constituye lo sagrado y por eso la santidad emerge como "esencia sin mezcla", como pureza que ha desmontado lo sagrado. Pero no hay que equivocarse, la santidad emerge a través de personas con rostro propio. Lévinas sostiene que la santidad es Espíritu porque ha animado al judaísmo en su esfuerzo por enfrentar la totalidad; ${ }^{14}$ pero, aunque Lévinas no lo diga explícitamente, la santidad también es Espíritu porque construye a la persona que hace el bien.

En el mismo sentido, Kant (1981) rechaza la medianía que promueve una religiosidad no moral ya que solo busca favores y más bien le opone una religión que es "un principio moral" por el

[...] que cada uno ha de hacer tanto como esté en sus fuerzas para hacerse un hombre mejor; y solo cuando no ha enterrado la moneda que le ha sido dada al nacer (Luc., XIX, 12-16), cuando ha empleado la disposición original al bien para hacerse un hombre mejor, puede esperar que lo que no está en su capacidad sea suplido por una cooperación más alta (p. 61).

13 Lévinas podrá referirse a lo sagrado con los mismos términos que al il y a (hay).

14 No podemos detenernos en las reflexiones de Lévinas en torno al judaísmo, pero su juicio ayuda a comprender su crítica ya no solo contra la totalidad, sino contra lo sagrado. 
Aunque Kant guarde silencio al respecto, la cita evidencia la intervención de la gracia no como sucedáneo de la virtud, sino como ayuda adicional a nuestro esfuerzo voluntario por ser mejores, por cumplir las condiciones del deber moral. Veamos cómo se articulan la posición kantiana y la Lévinasiana para extraer algunas consecuencias. ${ }^{15}$

Lévinas intenta explicar la distancia que existe entre lo sagrado y la santidad en el ámbito de este pensamiento. En efecto, la emergencia de la santidad supone primero la desacralización. Kant, por su parte, sostiene que la religión será moral cuando haga posible la mejora de la persona, pero esta posición lo hace ponerse en la perspectiva de una santidad que, a todas luces, ha adquirido un sentido ético:

El bien original es la santidad de las máximas en seguimiento del deber propio; por donde el hombre que acoge en su máxima esta pureza, si bien no por ello es ya santo él mismo (pues entre la máxima y el acto hay un gran trecho), sin embargo está en el camino de acercarse a la santidad en el progreso infinito ${ }^{16}$ (1981, p. 55).

Se puede decir que la aspiración a la santidad (al bien) va de la mano de cierta "convertibilidad" del ser humano, se convierte por y hacia la ley moral sobre cuya santidad Kant no tiene ninguna duda. Al detenernos en la convertibilidad de la persona no ponemos el interés en el cambio efectivo, sino en lo que la hace posible y, aunque obviamente lo que es bueno se puede corromper, estamos poniendo en valor la capacidad de desear ser

15 "Lo que Platón, Kant y Lévinas comparten -aunque muchos de los detalles cruciales de sus respectivos esquemas no pueden ser reconciliados- es una profunda desconfianza hacia cualquier experiencia religiosa que promueva rituales o prácticas que inducen al éxtasis en aras de la unión con lo sobrenatural" (Caruana, 2006, p. 563; Trad. propia). En efecto, aunque en nuestra investigación hemos preferido lo sagrado, en ocasiones Lévinas se refiere también a lo sobrenatural (Lévinas, 1961, p. 177).

16 No debe escapársenos que, en el caso de Kant, el sustantivo alemán Heiligkeit puede traducirse por santo o sagrado. Lo mismo ocurre con el adjetivo heilig. "Solo el contexto puede decidir el sentido preciso que conviene dar al sustantivo Heiligkeit" (Eisler, 1994, p. 933; Trad. propia). Asimismo, "una voluntad 'santa' sería una voluntad 'incapaz de máximas en oposición con la ley moral'” (Eisler, 1994; Trad. propia). 
mejor, de aspirar a hacer efectiva la ley moral. Esta condición se explica en razón de una identidad suficientemente plástica o permeable en virtud de un trabajo dedicado sobre sí mismo ${ }^{17}$.

Así pues, la santidad consiste en "querer ser mejor"; esto es, seguir las máximas de la ley moral. Sin embargo, podemos ir más lejos y preguntarnos si el "querer ser mejor" se agota en la esfera legal o moral, como parece sugerirlo Kant, y si no es más bien una cualidad espiritual como lo deja entrever Lévinas. El problema es que no estamos totalmente seguros de lo que Lévinas entiende por espiritual o por espiritualidad, aun cuando el término aparece en repetidas oportunidades en sus obras. ${ }^{18}$ Así pues, incluso habría que ir más allá de Lévinas y proponer un contenido que corresponda a la

17 William James al explicar la conversión religiosa sostiene que: "A partir de ahora hablaremos del lugar cálido en la conciencia de un hombre, del grupo de ideas que denominaremos el centro habitual de energía personal. Para un hombre existe una gran diferencia entre que sea un grupo de ideas u otro el centro de su energía, y también se establece una gran diferencia con respecto a cualquier grupo de ideas que posea, en tanto que éstas sean centrales o periféricas. Decir de un hombre que se ha "convertido" significa, en estos términos, que las ideas religiosas, antes periféricas en su conciencia, ocupan ahora un lugar central y que los objetivos religiosos constituyen el centro habitual de su energía" (1994, p. 94). En el presente caso, el autor norteamericano estudia la conversión efectiva en términos de un desplazamiento en la persona por la que las ideas antes periféricas pasan a ser nucleares; este desplazamiento religioso, que toma lugar en la conciencia, permite también entender la convertibilidad que aludimos: el individuo se modifica, pero además puede reordenar sus finalidades en una nueva dirección. Volvemos a James quien no está seguro de poder dar cuenta de qué es lo que se produce con exactitud en la conversión. "Si la gracia de Dios opera milagrosamente, a buen seguro lo hace por la puerta de lo subliminal. Pero todavía no se ha explicado cómo cualquier cosa actúa en este ámbito, y haremos bien en despedirnos del proceso de transformación -si queréis, lo dejaremos en un gran misterio psicológico o teológico para pasar a los frutos de la condición religiosa, sin importarnos la forma en que éstos han sido producidos" (1994, p. 128).

18 En Totalidad e infinito, el término spirituel aparece ocho veces y en De otro modo que ser o más allá de la esencia, cinco veces. La obra en la que se registra más repeticiones del término es Dificil libertad (setenta veces). Se podría hacer este ejercicio en todas las obras de Lévinas y se reconocería con relativa facilidad la insistencia en el vocablo. Asimismo, se podría repetir el ejercicio con el sustantivo spiritualité y las conclusiones serían análogas (Ciocan \& Hansel, 2005). 
intuición del término "espiritual". Es verdad, querer ser mejor no supondrá solamente encarnar una ley moral, sino incluso, desear más allá de toda previsión. Es como si la convertibilidad del individuo consistiera en la disposición para hacer el bien más allá de marcos previsibles como el legal. ${ }^{19}$ A este respecto, James menciona ejemplos de conversión que sorprenden por su despliegue práctico que, a todas luces, desafía la imaginación porque el individuo parece deshacerse en amor.

En consonancia con lo dicho hasta aquí, sostenemos que lo espiritual es una cualidad de la persona que consiste en su capacidad irrenunciable de convertirse, de ser mejor o de querer ser mejor. La espiritualidad no consistiría solamente en ajustarse a la ley moral o en cumplir con lo que ordena el tribunal de la razón, sino del hecho de representarse objetivos que superan límites y expectativas previsibles. Significa correr el riesgo de la esperanza de los mejores posibles. ${ }^{20}$ Esta forma de esperanza, aun cuando se exponga al fracaso, solo es practicable en un itinerario en el que no existe más fusión sagrada que domine la voluntad por el terror o por la fascinación. La espiritualidad es así un itinerario abierto hacia el infinito.

Con el término espiritual nos referimos, por lo tanto, a la condición de la persona por la que el infinito hace morada en ella sin identificarse con ella; esta experiencia de aquello que no soy explicaría por qué esta condición provoca que la persona sea incontenible en su movimiento de salida de sí. De facto, el encuentro sin parangón entre el infinito y la persona crea un fuera de sí, en adelante, el único espacio de cordura para la persona. Lo que queremos decir es que el infinito en la persona se ha convertido en exigencia de hacer o de realizar el bien como acto de cordura, como acto razonable.

19 De este modo aparece para nosotros la primera fenomenalización del infinito: 'querer ser mejor' expresa cómo el infinito se hace carne en nosotros como deseo de lo más y de lo mejor.

20 De vital importancia es suspender nuestra habitual necesidad de contar con "evidencia suficiente" como invoca William James al explicar que no puede ser más sabio ceder a nuestro temor y dejar de lado el hecho de que nuestra esperanza pueda ser verdadera $(2009$, p. 65). No es más sabio condenar nuestra esperanza. 


\section{La persona del santo}

Tras los pasos de Plotino, Agustín de Hipona se preguntaba: ¿de dónde proviene el mal? Y con el fin de responder a esta pregunta investiga primero acerca de su naturaleza. Como lo recordamos, su respuesta desontologiza el mal para hacerlo depender enteramente del libre albedrío del ser humano por el que la persona es capaz de desprenderse del orden de Dios. No hay pues mal sustancial, y con esta respuesta el Obispo de Hipona disolvía la confusión maniquea tal como lo señala explícitamente en La naturaleza del bien (1947). Para el obispo de Hipona, el mal no es aprendido; es contraído en virtud del pecado original. En este sentido, el mal nos precede y nos allegamos al mundo y a la historia cuando él ya se ha hecho viejo en nosotros. Pero la pregunta por el mal nos dispone para inquirir acerca de nuestra realidad para dar cuenta de nosotros mismos y de lo que somos.

Por esta razón, la pregunta de Agustín de Hipona sugiere otra como esta: ¿de dónde proviene el bien? E incluso mejor, ¿̇e dónde procede la santidad? Es decir, ¿cuándo entró en la historia y qué significa? Es verdad que la pregunta parece menos apremiante que aquella que indaga por el mal; peor aún, la tarea parece condenada al fracaso si nos ponemos a pensar en nuestra misteriosa "naturaleza" dispuesta al bien, pero inclinada al mal (Kant, 1981). Señala el filósofo alemán: “[c] uando se dice que el hombre ha sido creado bueno, ello no puede significar nada más que: ha sido creado para el bien, y la disposición original del hombre es buena" (p. 54). Por lo tanto, ¿por qué descuidar esta disposición humana hacia el bien especialmente si ella puede ayudar a pensar el desmontaje del mal, es decir de lo sagrado ${ }^{21}$ ? La respuesta a esta pregunta está en la persona del santo.

21 Asumimos, a riesgo nuestro, esta identificación entre el mal y lo sagrado. Tendríamos que hacer un itinerario epistemológico más extenso. En todo caso, se puede decir que el presente artículo muestra e insistirá todavía en la identificación que se produce entre lo sagrado y la violencia. Asimismo, Lévinas nos sirve de guía en nuestra identificación. El filósofo francés en una entrevista con Catherine Chalier habla expresamente del ser idéntico como el mal mismo o como raíz del mal (Lévinas, 1991). "El mal es inherente al ser", dirá Lévinas. Cierto, el ser avasalla con su lógica de conquista bajo la impronta de una alternativa sin escapatoria (ser o no ser). El ser nunca abandonará su deseo de conquista ni sus estrategias de sumisión del otro. En esto, lo sagrado es idéntico al ser: ser o no ser; unirse a lo sagrado o desaparecer. La filosofía de Lévinas no dejará de buscar caminos de salida a este ser monstruoso. 
El santo es quien hace el bien; quien, en cualquiera de sus versiones sorprende, como lo hace ver M. Ricard al explicar su relación y su impresión frente a los monjes budistas en el origen de su transformación.

Tuve la impresión de ver a unos seres que eran la imagen misma de aquello que enseñaban [...]; su aspecto era extraordinario. No lograba entender exactamente porqué, pero lo que más me llamaba la atención era que se correspondían con el ideal del santo, del ser perfecto, del sabio, una categoría de seres que, en apariencia, ya no es posible encontrar en Occidente (Revel y Ricard, 1998, p. 19).

Para William James (1994) la santidad refleja la madurez de la persona en una religión; ${ }^{22}$ asimismo, "el carácter santo es aquel para el cual las emociones espirituales son el centro habitual de la energía personal, y existe una panorámica compuesta por la santidad universal, la misma para todas las religiones de la cual podemos trazar fácilmente las características" (p. 128). Nosotros creemos que es posible ir más lejos, fuera del ámbito de las religiones, y encontrar un universal en el que coincidan quienes tengan una tonalidad afectiva que refleje su aspiración al bien. ${ }^{23}$ Entre las características del santo que enuncia James encontramos que este vive de modo abierto y más allá de intereses egoístas; experimenta una continuidad, es decir un vínculo de amistad con el "Poder Ideal" - o simplemente el bien - así como libertad y alegría y un cambio del "centro emocional hacia sentimientos de amor y armonía” (James, 1994, p. 128-ss). Habitualmente, de esta forma afectiva se sigue un conjunto de prácticas que James enumera y explica. Entre las prácticas mencionadas, y de las que damos cuenta según nuestra propia óptica, se encuentran el ascetismo (capacidad de ofrecerse), fortaleza de alma (capacidad de entereza), pureza (capacidad para "limpiar la existencia de elementos brutales y sensuales") y caridad (capacidad de salida de sí). Todo ello muestra visiblemente lo que llamaremos el reflejo del bien en la persona del santo.

22 Considero que la perfección de la persona que subraya el testimonio de Ricard podría corresponder con la madurez que reconoce James.

23 Nótese, entonces, que a este "querer ser mejor" o "querer el bien" que caracterizan al santo, le hacemos corresponder una tonalidad afectiva: un vínculo de amistad con el Poder ideal, una alegría y una reorientación de su centro emocional. 
El santo fenomenaliza la santidad o, dicho a la inversa, la santidad se hace fenómeno en la práctica buena, en la entrega; es decir en la acción que salva al otro; o que lo pone a buen recaudo. La ofrenda de la vida, fruto de madurez, emana del santo como una forma de trascendencia en la que por el don de sí se excede. En este sentido, no hay forma de cometer el bien sin renunciar a la consistencia de uno mismo; sin trascenderse. En ese gesto el santo también se libera de competencia o de comparación con otros porque su deseo no es ser mejor que otros, sino darse, aunque esto lo haga ser mejor que sí mismo y aunque, eventualmente, lo presente como personaje antipático para algunos. ${ }^{24} \mathrm{El}$ santo solo quiere "ser mejor" para el otro incluso cuando esto suponga romper con las formas que corresponden al orden establecido por la horda, el grupo, la institución.

Pese al rol del santo, todas las ciencias religiosas coinciden en la centralidad de lo sagrado cuando se busca explicar qué es una religión. Pero la realidad violenta de lo sagrado, así como la exigencia de pensar en la sociedad y el hecho de descubrir que la religión puede salir de la religión, hacen pensar que lo sagrado es el epifenómeno y que no hemos logrado dar cuenta del núcleo esencial que anima a las religiones y que explica el recurso permanente de los seres humanos a ellas. Esta intuición encuentra sustento en filósofos que han investigado el fenómeno de la religión desde la "socialidad", o mejor todavía, desde la posibilidad de la relación como lo hacen Buber o Lévinas. ${ }^{25}$

Aun cuando asumamos que no se equivoca Girard en su análisis sobre la unidad entre religión y cultura ni en la articulación entre ellas por vía de lo sagrado, el hecho de que él mismo sostenga la salida de la religión en la

24 "La antipatía hacia la santidad parece ser un resultado negativo del instinto biológicamente útil de acoger positivamente el liderazgo y glorificar el jefe de la tribu" (James, 1994, p. 175).

25 Buber (1979) ha explicado la centralidad que tienen las palabras primordiales yotú, yo-ello; se trata de palabras relación por las que se configura el yo. Lévinas ha insistido también en la relación, aunque nunca con un tú con el que se piensa una simetría, sino con otro que me observa desde arriba. Lévinas (2006) desea ir más allá de la religión de lo sagrado o de lo numinoso para situarse en la relación por la que el sujeto constata la interrupción de su buena conciencia. 
excepción cristiana obliga a hacer un análisis genealógico para dar con el corazón trastocado de las religiones. De allí todo el desarrollo previo que muestra un olvido o un descuido con respecto del santo y de la santidad. El santo no es solo la figura del héroe solitario en medio de una religión que no tiene relación con él; al contrario, la religión, como dimensión relacional, es la razón por la que el santo renuncia a la voluntad de poder sobre los demás. La cultura se inicia con la religión y esta con lo sagrado, como lo explica Girard; pero lo sagrado es la excrecencia adherida tempranamente sobre la experiencia originaria del bien; y es este último lo primero en el orden de las experiencias y no de los artefactos. La consistencia y la permanencia de las espiritualidades hablan en favor de esta tesis.

Lo sagrado estableció las condiciones de la cultura en términos de una totalidad, $y$, en correspondencia estricta con la medida del deseo mimético, no hemos sido capaces de liberarnos de lo sagrado. Y aunque el deseo sea mimético en su fisonomía, no se debería dar por sentado que nos conduciría inevitablemente en dirección de la totalidad única. A este respecto, la santidad es una divergencia que nos retrotrae sobre la experiencia de lo perdido, de lo primero, del infinito, del bien; el santo es el profeta de la espiritualidad. Su tenacidad hace pensable otro núcleo temático en las religiones.

\section{El santo inmerso en la espiritualidad del infinito}

Así las cosas, por el término y el hecho de la espiritualidad entendemos una disposición de la persona que consiste en abrirse a la experiencia del infinito, de la trascendencia o de Dios. Por lo tanto, el punto de partida de una espiritualidad se encuentra en el infinito cuya experiencia solo puede provocar una divergencia o disrupción con respecto del orden ya establecido y al que ya nos hemos acostumbrado. Como señala Lévinas (1995), es sobre el fondo del infinito que se conoce lo finito; de allí pues que lo finito permanezca abierto allende su propia persona o, lo que es lo mismo, que lo finito descubre que no se agota en sí mismo (Lévinas, 1995, p. 79). Este fondo del infinito, hecho experiencia de lo mejor y de lo más grande en la 
vida ordinaria, se fija en la persona a modo de característica propia. ${ }^{26}$ Esta experiencia que se ha hecho parte de la persona hace posible la ruptura o al menos la suspensión del eterno retorno de lo mismo de cualquier totalidad, del eterno retorno de lo sagrado, y hace posible reescribir la narrativa del sujeto con nuevos aires. El infinito hace posible la divergencia irrepetible del santo, su singularidad.

Pero este infinito, "esta trascendencia está viva en la relación con el otro hombre" (Lévinas, 1995, p. 131) y en el infinito inevitable de cada relación. Lo que quiere decir que el infinito es una posibilidad que se hace "efectiva" en el vínculo con el otro, en la relación sin ligaduras a condición de que antes haya hecho nido en algún lugar de la conciencia. ${ }^{27}$ Por esta experiencia que escapa a la síntesis fenomenológica, nos aproximamos de un infinito que no será jamás conocimiento en sentido estricto.

Ahora bien, el infinito, "conciencia de la conciencia", es la condición de posibilidad de la conversión. Vuelvo a la figura de la santidad ya que su quehacer muestra su origen y sus consecuencias. En efecto, la conversión en el santo emerge como un fenómeno nuevo por el que se aprecia una reorientación de ideales, deseos y acciones; la conversión se hace efectiva en el momento mismo en que una persona descubre la posibilidad de ser distinta de sí para hacerse al fondo sobre el que se reconoce distinta de esto en lo que ha devenido, pero idéntica de aquello que alberga por el hecho mismo de no estar atada a ella misma. A esto se le puede llamar querer al bien más que a sí mismo. Por eso puede decirse que convertirse es encontrarse con el

26 Es lo que mostramos al hablar de las características del santo. En este sentido, Newberg nos ofrece una explicación científica de las razones por las que cuanto más se recurre a la dimensión espiritual, tanto más la persona se hace familiar con ella (Big think, 2012). Asimismo, aunque el estudio insista sobre todo en la meditación al estilo budista, se puede consultar el libro de Daniel Goleman y Richard Davidson (2017).

27 Con el fin de eludir la tentación de hacerse de un infinito, Lévinas (1998) se referirá a esta experiencia en términos de una conciencia de la conciencia, conciencia preintencional o mala conciencia (p. 80). 
infinito o dejarse desmontar por él $;^{28}$ en virtud de este, el yo se ha abierto a posibles que ignoraba mientras solo era prolongación de una totalidad.

El hecho de la convertibilidad del ser humano, es decir el hecho de encontrar en él vestigios de su capacidad para cambiar la conducta y replanteársela como induce Kant, hace pensar que el deseo, aun cuando sea mimético, no habría suprimido ni el fondo ni el ejercicio de la voluntad por medio de la cual emerge la diferencia, por la que nos proponemos nuevas finalidades. No parece imposible que la persona que desea, en contacto con el infinito que lo inquieta, se convierta y se abra al fondo de la socialidad -contra la violencia. Dicho de otro modo, se puede esperar la conversión en quien se deja hacer por el infinito. ${ }^{29}$

Ahora bien, no es aconsejable ignorar el modo como se configura el deseo en la perspectiva que ha abierto Girard, pero podemos aspirar a una conversión ética y finalmente espiritual. ${ }^{30}$ Con esto quiero decir que es posible y necesario reconducir el deseo, exponerlo al infinito, ponerlo en posición de exilio de sí. ¿Qué significa esto? Si hemos seguido a Girard en

28 Lévinas usa el término "dénucléation" (desnucleación) para referirse al sujeto desmontado en su constitución propia (1974, p. 81). En el ámbito de la vida espiritual encontramos no pocas veces el testimonio del santo que experimenta el abismo de haber sido desmontado en el conjunto de evidencias y de certezas que había tenido hasta ese momento.

29 Fuera del ámbito de las religiones, esta conversión se esperará como fruto de una razón ordenada no exenta de voluntad y de afecto; en el ámbito confesional, se esperará además una ayuda de lo alto o de la gracia (como se expresa en la teología cristiana).

30 Jean-Luc Evard hace un estudio crítico de las paradojas que no puede evitar Girard en el desarrollo de su teoría mimética. Sin duda, la crítica que hace Girard de las ciencias sociales va tan lejos como se puede. El fracaso de estas en su esfuerzo por describir la existencia revela no solo el carácter excepcional de la existencia, sino que, en última instancia, como en Lévinas, ella se dice en términos de una ética: la teoría de Girard afirma que "[...] la apertura al otro, en lo que consiste lo primordial de la existencia, se resiste a toda regulación durable, no funda la 'sabiduría más urgente' a la que apelaba Lévinas" (Evard, 2004, pp. 307-308; Trad. propia). Pero al mismo tiempo, la teoría girardiana parece condenarnos a la violencia como una suerte de non plus ultra. 
su tesis en torno a lo sagrado y al deseo mimético, se trata de volverse al momento en el que el deseo es apertura, es condición sin condicionante; en el momento en el que el deseo crece sin posibilidad de ser satisfecho por ningún objeto. Ese momento se produce cuando el infinito que se hace desear se pone en contacto con el ser humano no con el fin de satisfacerlo, sino con el fin de inquietarlo, de abrirlo como manifiestamente repite Lévinas. Sobre este momento del que intentamos dar cuenta se puede reconocer que la persona es arrancada de su posición y se produce en ella un desfase cuya consecuencia es la conversión, es decir, el inicio de un posible "fuera de libreto". Este desfase se podría expresar en términos como: no soy yo quien vive en mí sino otro distinto de mí (Ga 2:20) o "vivo sin vivir en mí, y de tal manera espero, que muero porque no muero" como lo expresaba bellamente Teresa de Ávila. Diferentes espiritualidades nos habrán hecho sensibles no solo a la posibilidad de la transformación, sino a los beneficios de la misma.

\section{Conclusiones}

Este artículo ha procurado penetrar en el sentido de una dimensión muy presente en el siglo XXI: la espiritualidad. Para acceder a esta dimensión hemos dejado de lado lo sagrado y nos hemos abocado a la santidad. Si bien es cierto que la era secular se caracteriza por separar religión y espiritualidad, no es menos cierto que esto se debe a una comprensión limitada de aquello que inspira a las religiones; a saber, no lo sagrado, sino la santidad. No hemos querido hacer una definición cerrada del término espiritualidad porque parece lo opuesto a ella. Hemos propuesto en último término que esta dimensión es la capacidad para el infinito.

El presente artículo ha contrapuesto lo sagrado y la santidad para hacer evidente que el primer término, aunque forma parte del proceso de hominización y precisamente por ello se gesta en la configuración mimética del deseo, no es un absoluto. Lo sagrado es creado por el ser humano para constituir estructuras de conquista, de poder, de dominio, es decir, por lo sagrado se construyen y consolidan diferentes formas de totalidad. La santidad, fenómeno emergente habitualmente asociado a una dimensión 
ética, expresa que una persona quiere ser mejor; expresa su deseo de bien y rompe los límites de la repetición.

Un indicio tangible de la presencia de la dimensión de la espiritualidad en el ser humano es la posibilidad de conversión, es decir esta cualidad por la que la persona busca hacerse mejor, ser santa. Kant y Lévinas aluden a la santidad en sentidos distintos, pero sus interpretaciones confluyen en una dimensión ética. Con todo, hemos querido señalar que la santidad no se reduce a una condición ética (deber moral o responsabilidad), sino que nos transporta al ámbito de la espiritualidad no solo o no tanto por ser un universal, sino porque ella es el efecto del querer ser mejor más allá de los límites que nos propone la norma de la razón.

De la mano de Lévinas hemos apelado al infinito para dar cuenta de la razón por la cual es posible esperar no solo una conversión, sino el hecho mismo de la convertibilidad. Todo este hecho en el que interactúan infinito, conversión y santidad completan el sentido "abierto" e incompleto de la espiritualidad. Cierto, la espiritualidad es la posibilidad del infinito no solo porque nos reconocemos sobre el fondo de este, sino porque toda convertibilidad supone la posibilidad de no quedar sujeto a un modo de ser, ni a un ser de otro modo; sino a hacerse mejor. Hoy será cumplir mejor con la ley moral; mañana será hacer mejor el oficio de ser persona.

A partir de la recuperación del término santidad es posible hacerse una idea diferente de la religión y comprender mejor su base espiritual muy en boga en el presente. Las religiones se han construido no solo sobre la base de lo sagrado, sino sobre una base espiritual que hemos ubicado en la persona del santo que aspira al bien.

\section{Referencias}

Agustín, S. (1947). La naturaleza del bien. En Obras de San Agustin (M. Lanseros OSA, Trad., Vol. 3, págs. 973-1047). Madrid: BAC.

al-Fârâbî, A. N. (2009). Obras filosóficas y politicas. (R. Ramón Guerrero, Ed., \&

R. Ramón Guerrero, Trad.). Madrid: Trotta. 
Arendt, H. (2003). Eichmann en Jerusalén. Un estudio sobre la banalidad del mal. (C. Ribalta, Trad.). Barcelona: Lumen.

Buber, M. (1979). Yo y Tú. Buenos Aires: Nueva visión.

Camus, A. (1997). La Peste. (R. Chacel, Trad.). Barcelona: Edhasa.

Caruana, J. (2006). Not ethics, not ethics alone, but the Holy. Lévinas on ethics and holiness. Journal of Religious Ethics (JRE), 34(4), 561-583.

Chalier, C. (2006). Le grand dégrisement. Archives de philosophie, 69(4), 539-551.

Chauvin, D. P. (1904). Qu'est-ce qu'un saint? : essai de psychologie surnaturelle (Quatrième ed.). París: Librairie Bloud et Compagnie.

Ciocan, C., \& Hansel, G. (2005). Lévinas concordance. Netherlands: Springer.

Comte-Sponville, A. (2006). El alma del ateísmo. Introducción a una espiritualidad sin Dios. Barcelona, Buenos Aires, México: Paidós.

Congar, Y. (s.f.). Encyclopaedia Universalis (Voix: Sainteté). Encyclopaedia Universalis. París, París, Francia. Obtenido de https://www.universalis.fr

Eisler, R. (1994). Kant-Lexicon, II. París: Gallimard.

Eliade, M. (1981). Lo sagrado y lo profano (Cuarta ed.). (L. Gil, Trad.) Guadarrama / Punto Omega.

Evard, J.-L. (2004). L'idée de vérité chez René Girard. Archives de philosophie, 67(2), 305-320.

Fernández Hart, R. (2015). Creo luego existo. Revelación y religión en Lévinas. Lima: Fondo Editorial de la Universidad Antonio Ruiz de Montoya.

Fierro Valbuena, A., \& Roncallo Dow, S. (enero-junio de 2014). Entre porosidad y blindaje: el devenir de la identidad. Discusiones filosóficas, (24), 201-219.

Girard, R. (1977). Mensonge romantique et vérité romanesque. París: Grasset.

Girard, R. (1978). Des choses cachées depuis la fondation du monde. París: Grasset.

Girard, R. (1985). Mentira romántica y verdad novelesca. Barcelona: Anagrama.

Girard, R. (1998). La violence et le sacré. París: Hachette.

Goleman, D., \& Davidson, R. (2017). Rasgos alterados. La ciencia revela cómo la meditación transforma la mente, el cerebro y el cuerpo. Barcelona: B. 
James, W. (1994). Las variedades de la experiencia religiosa. Barcelona: Ediciones Península.

James, W. (2009). La voluntad de creer y otros ensayos de filosofía popular. (R. Vilà Vernis, Trad.). Barcelona: Marbot.

Kant. (1972). La religion dans les limites de la simple raison. París: Vrin.

Kant. (1981). La religión dentro de los límites de la mera razón. (F. M. Marzoa, Trad.). Madrid: Alianza Editorial.

Kant. (2001). Sur le mal radical dans la nature humaine. (F. Gain, Trad.). París: Editions rue d'Ulm.

Lévinas, E. (1961). Totalité et infini. La Haya: Martinus Nijhoff.

Lévinas, E. (1974). Autrement qu'être ou au-delà de l'essence. La Haye: Martinus Nijhoff.

Lévinas, E. (1977). Du sacré au saint. Cinq nouvelles lectures talmudiques. París: Minuit.

Lévinas, E. (1989). Écrit et sacré. En J. Vieillard-Baron, \& F. Kaplan, Introduction à la philosophie de la religion (págs. 353-362). París: Cerf.

Lévinas, E. (1991). Being in the Principle of War. (C. Chalier, Entrevistador) Arte (Europe). TV5. Obtenido de https://www.youtube.com/watch?v=-

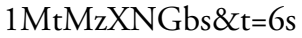

Lévinas, E. (1991). Entre nous. Essais sur le penser-à-l'autre. París: Grasset.

Lévinas, E. (1995). Altérité et transcendance. París: Fata Morgana.

Lévinas, E. (1998). Éthique comme philosophie première. París: Rivages poche.

Lévinas, E. (2004). De l'existence à l'existant. París: Vrin.

Lévinas, E. (2006). Ética como filosofía primera. (O. L. Gómez, Trad.) Santiago de Chile: Universidad de Chile. Obtenido de http://serbal.pntic.mec. es/ - cmunoz11/lorca43.pdf

Newberg, A. (5 de junio de 2012). Big think. Obtenido de https://www.youtube. $\mathrm{com} /$ watch? $\mathrm{v}=\mathrm{uxREBIWvxfk}$

Newberg, A., \& Waldman, M. R. (s.f.). How God changes your brain. New York: Ballantine books. 
La santidad perdida. Una revisión crítica de lo sagrado

Otto, R. (1996). Lo Santo. Lo racional y lo irracional en la idea de Dios. Madrid: Alianza.

Petitdemange, G. (1997). Lévinas. Phénoménologie et judaïsme. Recherches de science religieuse, 85(2), 225-247.

Ramond, C. (2009). Le vocabulaire de René Girard. París: Ellipses.

Revel, J.-F., \& Ricard, M. (1998). El monje y el filósofo. (J. J. Solar, Trad.). Barcelona: Ediciones Urano.

Tarot, C. (2008). Le symbolique et le sacré. París: La Découverte.

Taylor, C. (2003). Las variedades de la religión hoy. (R. Vilà, Trad.). Barcelona: Paidos. 
